\title{
EFFECT OF SEVEN JUMP LEARNING METHOD ON THE COMPETENCE TO USE PARTOGRAPH
}

\author{
Sutrisni \\ Diploma Program in Midwivery, Faculty of Public Health, Kadiri University
}

\begin{abstract}
Background: Problem-based learning (PBL) is a student-centered pedagogy in which students learn about a subject through the experience of solving an open-ended problem found in trigger material. The Maastricht seven-jump process in PBL involves clarifying terms, defining problem(s), brainstorming, structuring and hypothesis, learning objectives, independent study and synthesis. However, there is a like of previous studies that show the effectiveness of seven jump process and improving the competency of using of partograph. This study aimed to determine the effect of seven jump learning method on the competence to use partograph.

Subjects and Method: This was a quasi experiment using before and after intervention with no control design. This study was conducted at Faculty of Health Sciences, Kadiri University, Kediri, East Java. A sample of 35 students were selected for this study. The dependent variable was competence in using partograph. The independent variable was seven jump learning method of PBL. The data on the competence of using partograph was collected by direct observation and checklist. The data were analyzed by mcNemar chi square test.

Results: Number (percent) of students who demonstrated competence of using partograph increased from 19 (54\%) before seven jump to 29 (83\%) after seven jump, and it was statistically significant ( $\mathrm{p}=0.001)$.

Conclusion: The seven jump learning method can improve students competance of using partograph.
\end{abstract}

Keywords: seven jump method, partograph

Correspondence: Sutrisni. Diploma Program in Midwivery, Faculty of Public Health, Kadiri University, Jalan Selomangleng No.1, Kediri, East Java. 